\title{
The effect of the electrode tool material type on the surface roughness and tool wear in EDM
}

\author{
Abbas Fadhil Ibrahim ${ }^{1}$ \\ \{70011@uotechnology.edu.iq $\left.{ }^{1}\right\}$ \\ Production Engineering and Metallurgy, University of Technology-Baghdad-Iraq ${ }^{1}$
}

\begin{abstract}
Electrical discharge machining (EDM) is a nontraditional procedure for cutting brittle, hard materials and forming challenging forms. It is used to manufacture metal matrix compounds and very solid materials. This research focused on studying the effect of three different materials type of electrodes tool. The performance of electrodes produced from copper $(\mathrm{Cu})$, graphite $(\mathrm{Gr})$, and composite materials $(\mathrm{Cu}-\mathrm{Gr})$ specified is compared in assessing the roughness (Ra) of the workpiece and the electrode's wear (EW). These electrodes were used in a process to machine titanium alloy, aluminum alloy, and stainless steel 304 samples. Through the experiments and based on the data obtained, it has been proven that electrodes made of $(\mathrm{Cu}-\mathrm{Gr})$, some experiments, showed high performance and wear resistance (WR) than others, and to increase the electrical discharge machining processing efficiency of aluminum alloy and SS304, as well as for the processing of titanium alloy, concluded that it was suitable to use a tool produced of composite materials.
\end{abstract}

Keywords: EDM, electrodes wear (EW), Al- alloy, SS304, composite materials.

\section{Introduction}

One of the non-traditional machining's of electrostatic discharge machining (EDM) is mainly widely used frequently for cutting brittle, hard materials and for making difficult shapes [1]. Unwanted metals are separated and removed from the specimen by a series of repeated periodic electric sparks between the electrode and workpiece separated by a dielectric [2]. For the high-precision processing of all kinds of conductive materials, from alloys regardless of hardness, EDM is used in the manufacture of important parts, such as gearbox housings, copiers, and many others [3]. The main feature of this technology compared to other traditional machining methods is the ability of electrical discharge machining to machine any hard material, ensuring surface properties and high precision [4]. Determine the optimal solution and quality improvements of machined surface, with result in decreases in operating cost [5]. These components operate under variable loads and temperature conditions, high-strength materials are used, such as titanium-aluminum-tungsten-based alloys, thermally strengthened steel alloys, and others[6].

At present, several composite materials to wear resistance have been developed, which can enhance increase the WR of the tools compared to the materials used traditionally. The use of a composite material consisting of colloidal $\mathrm{Cu}-\mathrm{Gr}$ containing less than $2 \%$ graphite is one of the most used materials to solve this problem [7]. Electrode tools made of composite materials are produced using the metallic powder method. Thus, it is possible to change the technological standards and chemical composition of the powders used in the development of compounds to 
the electrode using this technique which makes it possible to greatly improve its properties [8]. Le Hong Ky et.al [9] designed some parameters and analyzed them according to the Taguchi method with an orthogonal array. Also, were investigated the input parameters such as Pon, Poff, Ip, and Sv. The effect of these factors on the Ra was estimated by analyzing variance. Using a Tungsten: Copper composite electrode, J Prasanna et al. [10] investigate tool wear rate (TWR) and material removal rate (MRR). The Ra of electrical discharge machine samples with Electrode Tool (ET) materials was examined by T Ablyaz et al [11]. Three distinct types of ETs were explored for the trials, each constructed of a different material: composite, copper, and graphite. The workpiece materials were chosen from aluminium, low alloy 35GS steel, and OT4 titanium alloy. Maradona and Wykes [12] used the Taguchi approach to provide a new way for optimising the removal rate of EDM using $\mathrm{Cu}-\mathrm{W}$ tools, resulting in an increase in MRR. When Goyal et al. [13] compared the MRR and TWR of pure copper and copper tungsten tools, they discovered that composite material tools have better performance and wear resistance. Through a review of the literature, it was found that it is necessary to study the characteristics of tools produced from composite materials to enhancement machining dissimilar alloys Also, this paper aims to verify the performance of electrode tools to surface roughness and wear resistance when the operation of titanium alloy, aluminum alloy and stainless steel 304.

\section{Experimental Procedure}

Taguchi method was used to designed and analyzed the experiment's work. Also, five input parameters including the workpiece material, electrode material, Ip, Pon, and Poff, were selected for the investigation. CNC-based EDM machine (CHEMER CM 323C), as illustrated in Fig 1 was used in experiments. Copper, graphite, and composites containing copper and $2 \%$ graphite were used in the manufacture of the electrodes Fig 2. The physical properties of three types of electrodes as shown in Table 1 The workpiece of Ti- alloy, Al- alloy 6061, and SS 304 were prepared of dissimilar materials. The independent process factor levels for EDM are described in Table 2. 


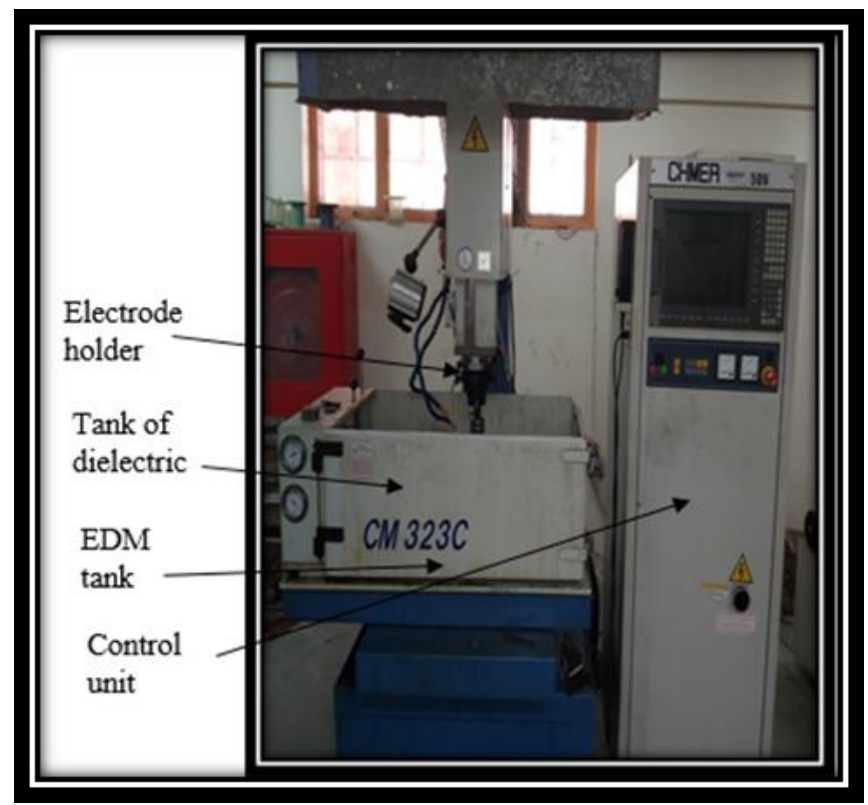

Fig 1. EDM CM323C CNC Machine.

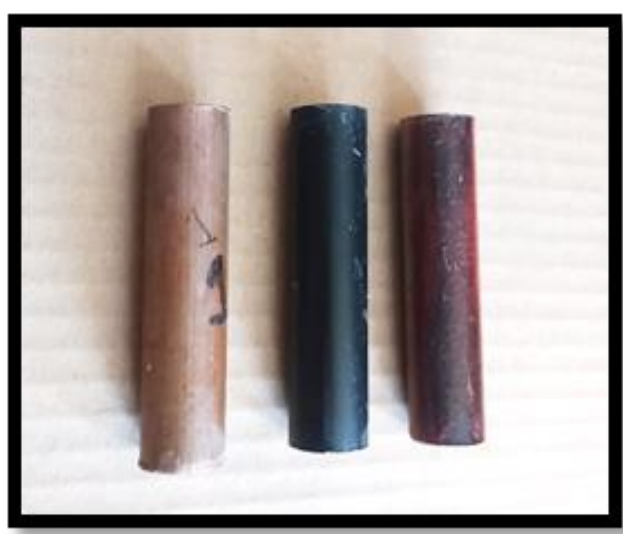

Fig 2. Three types of electrode tools.

Table 1. Physical properties of copper, graphite, and copper-graphite electrode.

\begin{tabular}{|c|c|c|c|}
\hline $\begin{array}{l}\text { Physical properties } \\
\text { graphite }\end{array}$ & Copper & Graphite & copper - \\
\hline Electrical resisitively $(\mu \Omega / \mathrm{cm})$ & 1.96 & 0.12 & 1.81 \\
\hline $\begin{array}{l}\text { Electrical conductivity compared } \\
\text { With Silver }(\%)\end{array}$ & 92 & 0.11 & 87 \\
\hline Thermal conductivity (W/mK) & 380.7 & 160 & 367 \\
\hline Melting point $\left({ }^{\circ} \mathrm{C}\right)$ & 1083 & 455 & 1118 \\
\hline Specific heat $\left(\mathrm{cal} / \mathrm{g}^{\circ} \mathrm{C}\right)$ & 0.092 & 0.18 & 0.11 \\
\hline Specific gravity at $20^{\circ} \mathrm{C}\left(\mathrm{g} / \mathrm{cm}^{3}\right)$ & 8.9 & 1.75 & 8.4 \\
\hline
\end{tabular}




\begin{tabular}{|c|c|c|c|}
\hline $\begin{array}{l}\text { Coefficient of thermal } \\
\text { Expansion }\left(x 10^{-60} \mathrm{C}^{-1}\right)\end{array}$ & 6.6 & 7.8 & 6.9 \\
\hline
\end{tabular}

Table 2. Input process parameters for EDM.

\begin{tabular}{lllc}
\hline Factor & \multicolumn{3}{c}{ Level } \\
& 1 & 2 & 3 \\
\hline Workpiece material & Titanium alloy & Aluminum alloy & SS304 \\
Electrode material & Copper & Graphite & Copper-graphite \\
Current $($ A) & 10 & 20 & 30 \\
Pulse on time $(\mu \mathrm{sec})$ & 100 & 150 & 200 \\
Pulse off time $(\mu \mathrm{sec})$ & 6 & 12 & 18 \\
\hline
\end{tabular}

An orthogonal matrix L27 (35) (27 tests, 5 factors, 3 levels) was created. After all of the studies, the surface roughness $(\mathrm{Ra})$ was determined using a portable Maher Federals surface roughness gauge. The weight of the tool was also monitored in this experiment to track volumetric loss owing to abrasive wear as a result of machining.

\section{Methodology}

The Taguchi method and analysis of variance (ANOVA) were used to determine the influence and contribution of input factors in the experimental data analysis.

\subsection{Taguchi}

It is frequently used as a powerful programme for assessing process parameters in all applications [14]. In this study, a specially built orthogonal array from Taguchi was utilised to explore the impacts of processing factors in a small number of experiments, which requires less time.

\subsection{Signal-to-Noise $(\mathrm{S} / \mathrm{N})$ ratio characteristics}

The signal-to-noise ratio was employed to assess experimental design modifications. The term signal denotes a desired value, whereas the term noise denotes an unfavourable value [15]. The $\mathrm{S} / \mathrm{N}$ ratio is calculated using the following equation to produce the least $\mathrm{Ra}$ and TW:

$\mathrm{S} / \mathrm{N}=-10 \log \left[\frac{1}{\mathrm{n}} \sum_{\mathrm{i}=1}^{\mathrm{n}}\left(\mathrm{y}^{2}\right)\right]$

Where n: number of replications.

yi: observed response value

\section{Results and Analysis}

According to the design of experiments (DOE) by the Taguchi method, the results of the experimental work for $(\mathrm{Ra})$ and (ER) are presented in Table 3. The highest quality was obtained in evaluating the surface roughness of the machine surface by using an electrode tool made of 
copper. The electrode produced from $(\mathrm{Cu}-\mathrm{Gr})$ possesses 2.5- and 1.1-times higher surface quality than the electrode produced from $\mathrm{Cu}$ and $\mathrm{Gr}$ respectively. By analyzing the wear resistance results of titanium samples, it was found that the copper-graphite electrode has a resistance of 1.2 times higher than that of the control. During the experiments, the parts of the particle were adhesion to the work of electrode surface and thus the weight of the graphite electrode increased after the operation.

Table 3. Design of experimental and the output response.

\begin{tabular}{lccccccc}
\hline No. & Workpiece material & Electrode material & current(A) & Pon $(\mu \mathrm{s})$ & Poff $(\mu \mathrm{s})$ & $\mathrm{Ra}(\mu \mathrm{m})$ & $\mathrm{Ew}(\mathrm{gr})$ \\
\hline 1 & Ti-alloy & $\mathrm{Cu}$ & 10 & 100 & 6 & 2.386 & 0.0036 \\
2 & Ti- alloy & $\mathrm{Cu}$ & 10 & 100 & 12 & 2.314 & 0.0032 \\
3 & Ti- alloy & $\mathrm{Cu}$ & 10 & 100 & 18 & 2.311 & 0.0027 \\
4 & Ti- alloy & $\mathrm{Gr}$ & 20 & 150 & 6 & 3.771 & 0.0000 \\
5 & Ti- alloy & $\mathrm{Gr}$ & 20 & 150 & 12 & 3.655 & 0.0000 \\
6 & Ti- alloy & $\mathrm{Gr}$ & 20 & 150 & 18 & 3.672 & 0.0000 \\
7 & Ti- alloy & $\mathrm{Cu}-\mathrm{Gr}$ & 30 & 200 & 6 & 4.923 & 0.0028 \\
8 & Ti-alloy & $\mathrm{Cu}-\mathrm{Gr}$ & 30 & 200 & 12 & 4.841 & 0.0026 \\
9 & Ti- alloy & $\mathrm{Cu}-\mathrm{Gr}$ & 30 & 200 & 18 & 4.872 & 0.0022 \\
10 & Al- alloy & $\mathrm{Cu}$ & 20 & 200 & 6 & 7.438 & 0.0017 \\
11 & Al- alloy & $\mathrm{Cu}$ & 20 & 200 & 12 & 7.116 & 0.0014 \\
12 & Al- alloy & $\mathrm{Cu}$ & 20 & 200 & 18 & 6.846 & 0.0014 \\
13 & Al- alloy & $\mathrm{Gr}$ & 30 & 100 & 6 & 6.845 & 0.0000 \\
14 & Al- alloy & $\mathrm{Gr}$ & 30 & 100 & 12 & 6.822 & 0.0000 \\
15 & Al- alloy & $\mathrm{Gr}$ & 30 & 100 & 18 & 6.607 & 0.0000 \\
16 & Al- alloy & $\mathrm{Cu}-\mathrm{Gr}$ & 10 & 150 & 6 & 8.117 & 0.0006 \\
17 & Al- alloy & $\mathrm{Cu}-\mathrm{Gr}$ & 10 & 150 & 12 & 7.593 & 0.0006 \\
18 & Al- alloy & $\mathrm{Cu}-\mathrm{Gr}$ & 10 & 150 & 18 & 7.734 & 0.0004 \\
19 & SS304 & $\mathrm{Cu}$ & 30 & 150 & 6 & 5.296 & 0.0037 \\
20 & SS304 & $\mathrm{Cu}$ & 30 & 150 & 12 & 5.246 & 0.0032 \\
21 & SS304 & $\mathrm{Cu}$ & 30 & 150 & 18 & 5.337 & 0.0025 \\
22 & SS304 & $\mathrm{Gr}$ & 10 & 200 & 6 & 4.978 & 0.0000 \\
23 & SS304 & $\mathrm{Gr}$ & 10 & 200 & 12 & 4.836 & 0.0000 \\
24 & SS304 & $\mathrm{Gr}$ & 10 & 200 & 18 & 4.811 & 0.0000 \\
25 & SS304 & $\mathrm{Cu}-\mathrm{Gr}$ & 20 & 100 & 6 & 6.721 & 0.0004 \\
26 & SS304 & $\mathrm{Cu}-\mathrm{Gr}$ & 20 & 100 & 12 & 6.744 & 0.0002 \\
27 & SS304 & $\mathrm{Cu}-\mathrm{Gr}$ & 20 & 100 & 18 & 6.578 & 0.0002 \\
\hline
\end{tabular}

From Table 3. It was observed that when operating the aluminum alloy, the wear resistance of the $\mathrm{Cu}-\mathrm{Gr}$ electrode tool was increased by an amount3.3 times higher wear strength than the tool produced from $\mathrm{Cu}$, but the $\mathrm{Ra}$ when using the tool produced from copper-graphite possesses was 0.4- and 0.7-times higher surface quality than the tool produced from copper and graphite respectively and enhanced significantly than other electrodes.

An analysis of the obtained data using SS304 showed that a tool produced from $\mathrm{Cu}-\mathrm{Gr}$ possesses a wear resistance that is 4.5 times higher than that of a tool made of $\mathrm{Cu}$. It also gives a lower surface quality than copper and graphite. While the highest surface quality obtained was when using the graphite tool.

The influence of parameters workpiece material, electrode material, (Ip), (Pon), and (Poff) on the surface roughness is shown in Fig 3. the Ra decreases upon decreasing the (Pon), and (Ip). Experiments have demonstrated that the workpiece and electrode material have an effect on improving surface roughness, with the titanium alloy as the workpiece and copper as the 
electrode material reducing surface roughness. The depth of the EDM's drilling surface grows as peak current increases, resulting in a larger value of Ra. These variables affect the power input, and it's possible that a lower power input enhances the surface polish.

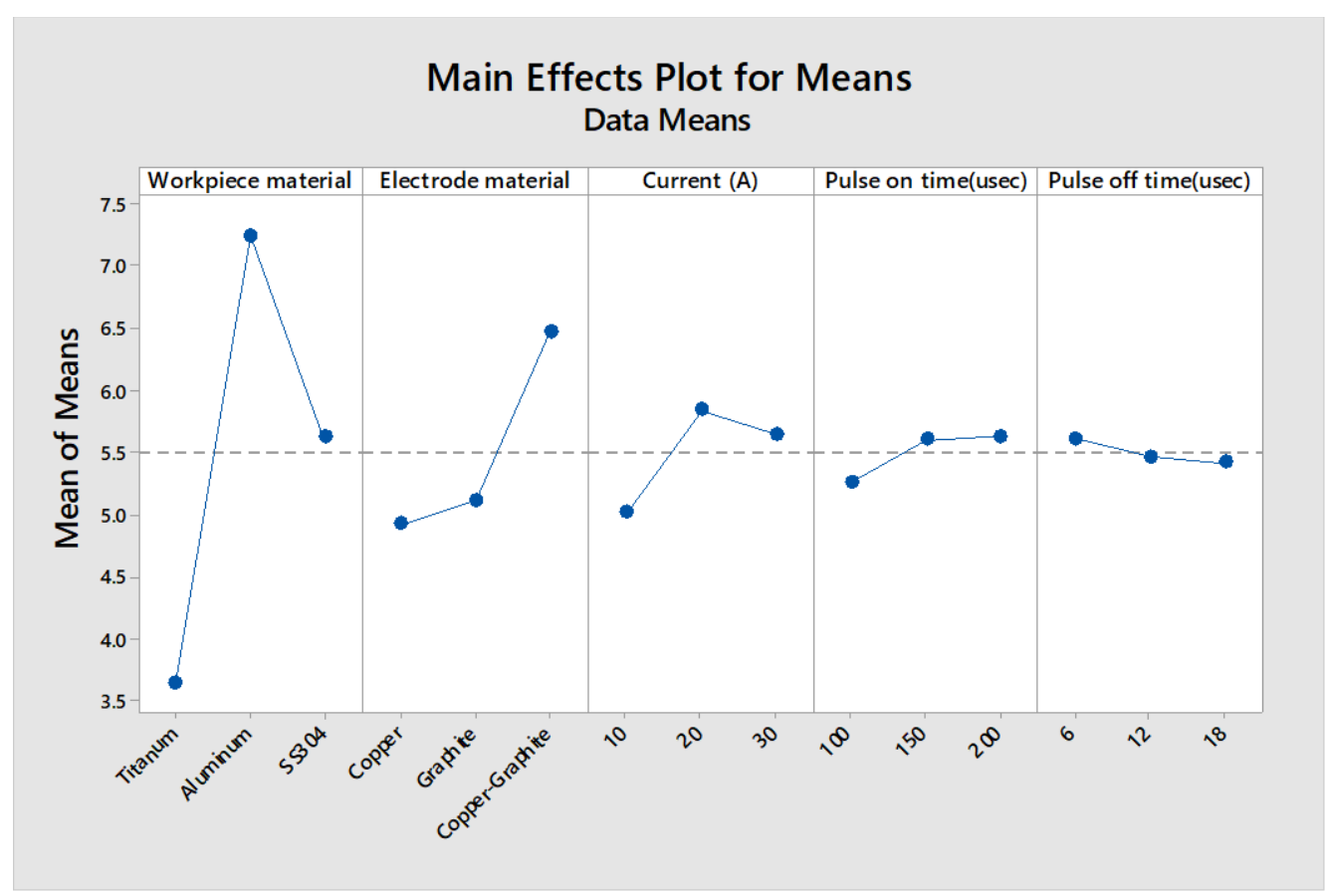

Fig 3. Main effects of each parameter on surface roughness.

The influence of process parameters on electrode wear is shown in Fig. 4. The electrode wear increases with using titanium alloy as workpiece and copper material as electrode tool increasing Pon, and Ip. Due to the increased cutting speed, more energy is delivered to the cutting process as the pulse duration increases. Increasing the current causes the Pon to rise, which improves the cutting rate even more. 


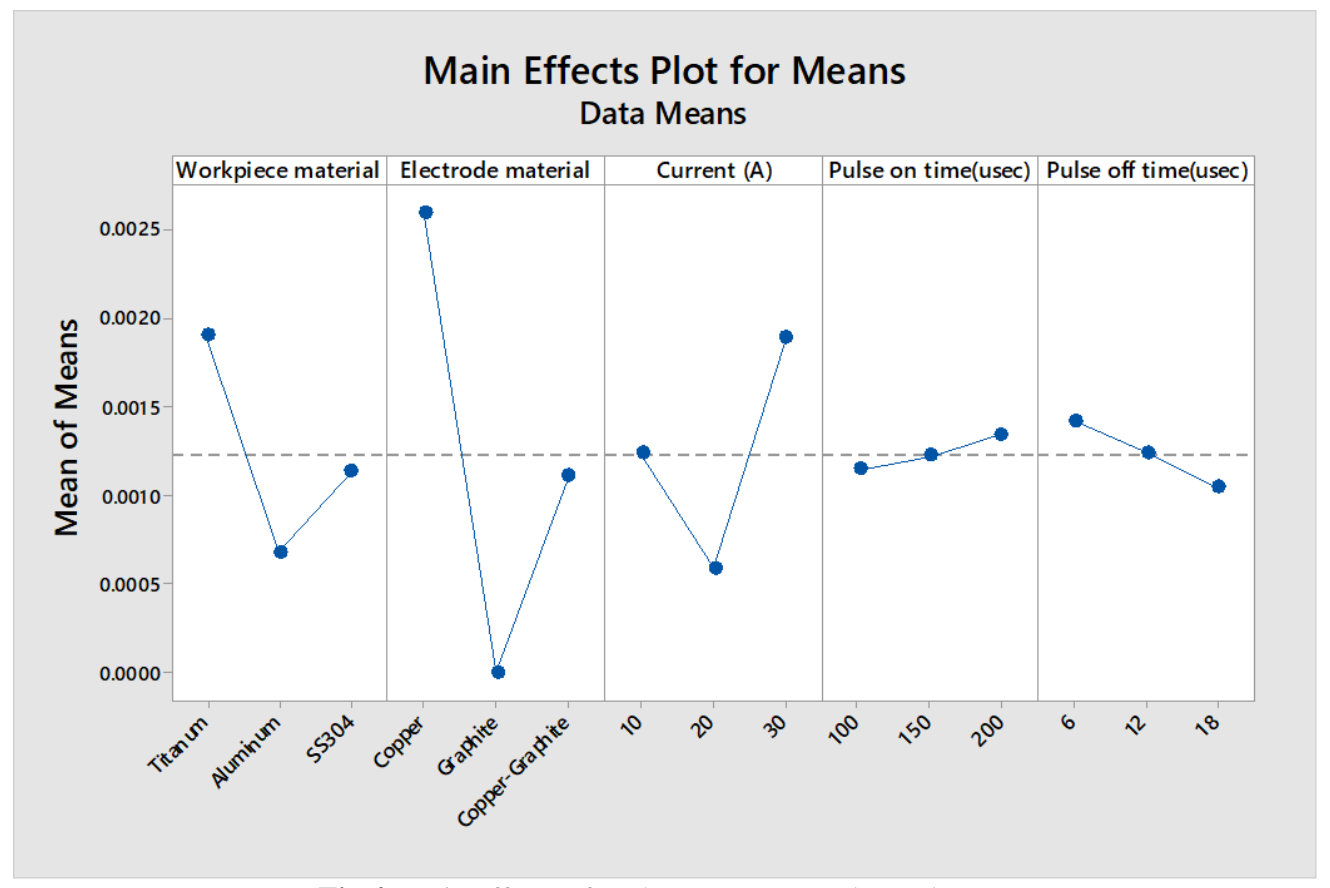

Fig 4. Main effects of each parameter on electrode wear.

\section{Conclusions}

Three types of electrode tool material on surface roughness and tool wear by using three dissimilar workpieces in EDM sinking by the Taguchi design method has been presented. Based on analyzing the data obtained from the experiments, it can be concluded that :

1- The highest surface quality obtained was when using the graphite tool, while the lower surface quality obtained was when using the composite electrode.

2-When a composite material is used for the electrode, some experiments, showed high performance and wear resistance than others and increase the electrical discharge machining processing efficiency of aluminum alloy and SS304, as well as for processing raw EDM of titanium alloy.

3- Concluded that it was suitable to use a tool produced of composite materials.

\section{References}

[1] K. Ojha, R. K. Garg, and K. K. Singh. MRR Improvement in Sinking Electrical Discharge Machining: A Review, Journal of Minerals \& Materials Characterization \& Engineering,2010, 9(8), p. 709-739.

[2] S. B. Chikalthankar, V. M. Nandedkar, S. V. Borde, 2013 Experimental Investigations of EDM Parameters, International Journal of Engineering Research and Development.2013, 7, p. 31-34.

[3] ShazarelShamsudin, Mohamed ShaikYusof. Electrical Discharge Machining (EDM) Of Beryllium Copper Alloys Using Design Of Experiment (Doe) Approach, International Engineering Convention, Damascus Syria.2009, 11, p. 257- 268. 
[4] Yeliseyev Y, Savushkin B EDM of aerospace products (Moscow: MSTU him NE. Bauman),2010 , p 437.

[5] KapoorJatinder, Singh Sehijpal and KhambaJaimal, Effect of cryogenic treated brass wire electrode on material removal rate in wire electrical discharge machining, Proceedings of the Institutionof Mechanical Engineers, Part C: Journal of Mechanical Engineering Science. 2012, 226(11), p. 2750-58.

[6] A O Grisharin, N D Ogleznev, K R Muratov, T R Ablyaz, S B Preetkanwal and S SSarabjeet, Investigation of the machinability of composite materials electrode-tools while EDM,IOP Conf. Series: Materials Science and Engineering.2019, 510.

[7] Grisharin A, Ablyaz T and Ogleznev N 2017 Improving the efficiency of machining parts of hydraulic cylinders and special-purpose products through the use of electrode tools with enhanced electroerosion properties (Perm: Perm national research polytechnic university, University Press) p 151.

[8] Bains P, Payal H and Sidhu S 2017 Analysis of Coefficient of Thermal Expansion and Thermal Conductivity of Bi-Modal SiC/A356 Composites Fabricated via Powder Metallurgy Route doi:10.1115/ht2017-5122.

[9] Le Hong Ky1, Tran Thi Hong2, Nguyen Van Cuong3, Tran Thanh Hoang4, Do Thi Tam4, LuuAnh Tung4, Nguyen Thanh Tu4, Vu Ngoc Pi4, Effect of Electrical Discharge Machining on Surface Roughness of Cylindrical Shaped Parts , Key Engineering Materials, Vol. 853, pp 13-17,2020.

[10] N. Beri, S. Maheshwari , C. Sharma, and Kumar, "Optimization of electrical discharge machining process with $\mathrm{CuW}$ powder metallurgy electrode using grey relation theory". International Journal of Machining and Machinability of Materials, Vol. 9, No.1/2, pp. 103 - 115, 2011.

[11] T Ablyaz1, E Shlykov1, K Muratov1, S Oglezneva1, V Karmanov1, I Osinnikov1, S S Sarabjeet2 and D Sahil, Experimental analysis of the EDM process of dissimilar materials, IOP Conf. Series: Materials Science and Engineering 754 (2020).

[12] P. Goyal, "Enhancement of MRR in EDM by composite material electrode on die steel," International Journal of Science, Engineering and Technology Research (IJSETR), Vol 3, Issue 10, October 2014.

[13] J. Prasanna, S .Rajamanickam, K. O. Amit , and R. G . Karthick, "Sathya Narayanan P V. MRR and TWR evaluation on electrical discharge machining of Ti-6Al-4V using tungsten : copper composite electrode," Frontiers in Automobile and Mechanical Engineering, IOP Conference Series: Materials Science and Engineering, PP. 197 - 012087, 2017.

[14] Abbas F. Ibrahim, Abdullah F. Huayier , Naeem A. Abdulhusein 2021 Influence of machining parameters on material removal rate in chemical machining of silicon carbide (SIC), Journal of Physics: Conference Series 1818 .

[15] Abbas Fadhil Ibrahim and Ali Mundher Mustafa 2019 Experimental investigation of machining parameters on material removal rate and surface roughness in chemical machining, IOP Conf. Series: Materials Science and Engineering 518 . 